\title{
Oxide-Based Electric-Double-Layer Thin-Film Transistors on a Flexible Substrate
}

DOI:

10.1109/LED.2017.2768822

\section{Document Version}

Accepted author manuscript

Link to publication record in Manchester Research Explorer

\section{Citation for published version (APA):}

Cai, W., Zhang, J., Wilson, J., Ma, X., Wang, H., Zhang, X., Qian Xin, \& Song, A. (2017). Oxide-Based ElectricDouble-Layer Thin-Film Transistors on a Flexible Substrate. IEEE Electron Device Letters, 38(12), 1680-1683. https://doi.org/10.1109/LED.2017.2768822

\section{Published in:}

IEEE Electron Device Letters

\section{Citing this paper}

Please note that where the full-text provided on Manchester Research Explorer is the Author Accepted Manuscript or Proof version this may differ from the final Published version. If citing, it is advised that you check and use the publisher's definitive version.

\section{General rights}

Copyright and moral rights for the publications made accessible in the Research Explorer are retained by the authors and/or other copyright owners and it is a condition of accessing publications that users recognise and abide by the legal requirements associated with these rights.

\section{Takedown policy}

If you believe that this document breaches copyright please refer to the University of Manchester's Takedown Procedures [http://man.ac.uk/04Y6Bo] or contact uml.scholarlycommunications@manchester.ac.uk providing relevant details, so we can investigate your claim.

\section{OPEN ACCESS}




\title{
Oxide-Based Electric-Double-Layer Thin-Film Transistors on a Flexible Substrate
}

\author{
Wensi Cai, Jiawei Zhang, Joshua Wilson, Xiaochen Ma, Hanbin Wang, Xijian Zhang, Qian Xin, and \\ Aimin Song, Senior Member, IEEE
}

\begin{abstract}
Flexible electric-double-layer (EDL) InGaZnO thin-film transistors (TFTs) were fabricated on a plastic substrate at room temperature. A large EDL gate capacitance, $0.22 \mu \mathrm{F} / \mathrm{cm}^{2}$, at $20 \mathrm{~Hz}$ was achieved using 200 -nm-thick radiofrequency magnetron sputtered porous $\mathrm{SiO}_{2}$ as the dielectric layer, which is equivalent to $\sim 15.7 \mathrm{~nm}$ thermally grown $\mathrm{SiO}_{2}$. The devices therefore show a low operating voltage of $1 \mathrm{~V}$, a high current on-off ratio $>10^{5}$ and a low subthreshold swing $<0.12 \mathrm{~V} / \mathrm{dec}$. These properties were maintained even after bending, suggesting that the TFTs are suitable for applications in portable sensors and rollable displays.
\end{abstract}

Index Terms - Electric-double-layer (EDL), flexible thin-film transistors (TFTs), radio-frequency magnetron sputtered $\mathrm{SiO}_{2}$, InGaZnO.

\section{INTRODUCTION}

$\mathrm{O}$ xide-based thin film transistors (TFTs) have gained significant attention especially in recent years due to their large field-effect mobility, low process temperature and largearea uniformity [1-4]. Electronic devices fabricated on flexible substrates provide technological solutions to many applications that cannot be achieved with conventional Sibased ones, such as mechanical flexibility and optical transparency [5]. However, most flexible TFTs require a large operating voltage, leading to high power consumption - a critical barrier to the realization of battery-powered portable electronics [6].

A common method employed to reduce the operating voltage is to reduce the thickness of dielectric layer, e.g. using ultra-thin cross-linked films or self-assembled monolayers [7, 8]. However, such transistors normally suffer large gate leakages due to the difficulty of maintaining good uniformity

This paragraph of the first footnote will contain the date on which you submitted your paper for review. This work was supported by the Engineering and Physical Sciences Research Council (EPSRC) (Grant No. EP/N021258/1), North-West Nanoscience Doctoral Training Centre, EPSRC (Grant No. EP/G03737X/1), National Key Research and Development Program of China (Grant Nos. 2016YFA0301200), National Natural Science Foundation of China (Grant Nos. 11374185 and 11304180).

W. Cai, J. Zhang, J. Wilson, X. Ma and A. Song are with School of Electrical and Electronic Engineering, The University of Manchester, Manchester M13 9PL, UK (email: A.song@manchester.ac.uk).

H. Wang, X. Zhang, and Q. Xin are with the Center of Nanoelectronics and School of Microelectronics, Shandong University, Jinan 250100, China (e-mail: xinq@sdu.edu.cn). over large area. An alternative is to use high relative permittivity (high- $\kappa)$ dielectric materials as they can increase the capacitive coupling between the gate electrode and channel layer $[9,10]$. However, such high-א dielectric materials usually have problems with threshold voltage control and therefore serious issues with long-term reliability [11].

Recently, some electronically insulating but ion-conducting electrolytes have been used to solve the problem. The most commonly used electrolytes are ionic liquids (ion gels) and polymer electrolytes (polyelectrolytes) $[12,13]$. However, it is hard to control the shape, thickness and uniformity of ionic liquids and ion gels. Polymer electrolytes also have limitations in stability, especially at high temperatures. As a result of these limitations, solid-state insulators with porous structures have been developed $[14,15]$. Such porous structures allow ions to diffuse, leading to high ionic conductivities. Under a positive gate voltage, the electric field drives the positive mobile ions, such as protons, towards the interface between the electrolyte and the semiconductor channel, and thereby induces electrons within the channel layer. The formation of an electric-double-layer at the interface gives a relatively high specific capacitance and ensures the TFT has a low operating voltage [16]. Plasma-enhanced chemical vapor deposition (PECVD)-deposited porous $\mathrm{SiO}_{2}$ has been demonstrated as a suitable solid-state electrolyte candidate [17, 18]. Hydrogen molecules from $\mathrm{SiH}_{4}$ in the plasma are believed able to enter the porous $\mathrm{SiO}_{2}$ layer and induce mobile protons inside the $\mathrm{SiO}_{2}$ layer to form a three-coordinate oxygen center, $\mathrm{Si}-\mathrm{OH}^{+}-$ Si [18]. Since the bonds are not stable, protons hop between two neighboring hydroxyl groups and move to the dielectric/gate interface or dielectric/channel interface according to the polarity of the external electric field $[19,20]$. However, PECVD might have toxic, explosive and flammable processing gases and by-products. We recently used radiofrequency (RF) magnetron sputtering to develop a costeffective, industry compatible way to deposit a porous $\mathrm{SiO}_{2}$ electrolyte that uses absorbed water molecules to generate mobile protons $[20,21]$.

In this letter, we report electric-double-layer transistors on polyethylene naphthalate (PEN) substrates fabricated at room temperature using RF magnetron sputtering. The devices have an operating voltage of $1 \mathrm{~V}$ and show excellent electrical properties with a current on-off ratio $>10^{5}$, a subthreshold swing $<0.12 \mathrm{~V} / \mathrm{dec}$ before and after bending. 


\section{EXPERIMENTAL PROCEDURE}

Flexible InGaZnO (IGZO)-based TFTs with a bottom-gate, top-contact structure were fabricated on PEN substrates at room temperature. Firstly, a 200-nm-thick polymethyl methacrylate (PMMA) layer was spin-coated on to the PEN to improve the smoothness of the substrate. 100-nm-thick Al was thermally evaporated to form the gate electrode. Using a $\mathrm{SiO}_{2}$ target, a 200-nm-thick $\mathrm{SiO}_{2}$ gate dielectric layer was deposited at $85 \mathrm{~W}$ by RF magnetron sputtering. A 70-nm-thick IGZO (In:Ga: $\mathrm{Zn}=1: 1: 1$ ) channel layer was deposited at $40 \mathrm{~W}$ by RF magnetron sputtering. Finally, 100-nm-thick Al source and drain were deposited by thermal evaporation. All the sputtering processes were kept at a pressure of $5 \times 10^{-3} \mathrm{mbar}$ in pure Ar ambient and all layers were patterned using shadow masks. Following the deposition of each layer, the samples were brought to atmospheric pressure and removed from the chamber. The channel length and width are $60 \mu \mathrm{m}$ and $2 \mathrm{~mm}$, respectively.

A schematic diagram of the devices is shown in Fig. 1(a). Fig. 1(b) shows the PEN TFT arrays on the probe station for electrical measurement on a curved surface, indicating the flexibility. The devices were measured using an Agilent E5270B semiconductor analyser and an Agilent E4980A LCR meter in air ambient. The cross-sectional views of $\mathrm{SiO}_{2}$ and IGZO were investigated using a FEI Nova NanoSEM 450 scanning electron microscope (SEM).

(a)
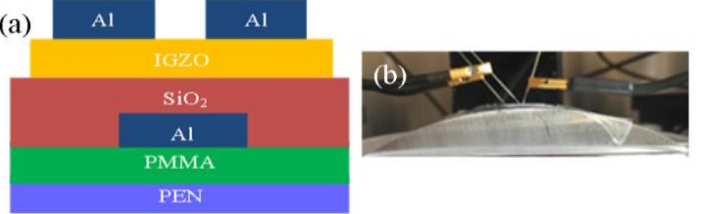

Fig. 1. (a) Schematic diagram of flexible EDL TFTs. (b) Optical image of the electrical measurement of PEN TFT arrays bent on a curved surface with a curvature radius of $3.5 \mathrm{~cm}$.

\section{RESULTS AND ANALYSIS}
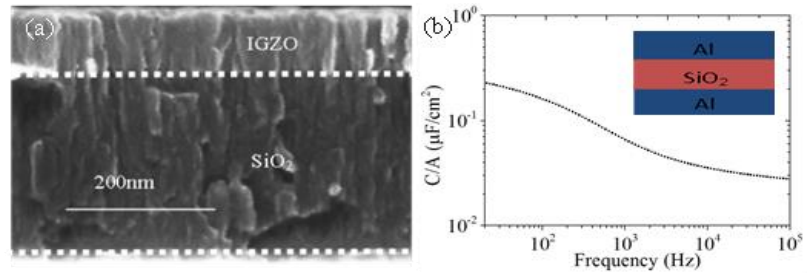

Fig. 2. (a) Cross-sectional SEM image of $\mathrm{SiO}_{2}$ and IGZO layers. (b) Specific capacitance of $\mathrm{SiO}_{2}$ gate dielectric as a function of frequency $(20 \mathrm{~Hz}$ to $100 \mathrm{kHz}$ ) with inset showing the capacitance test structure.

Fig. 2(a) shows the SEM of the $\mathrm{SiO}_{2}$ gate dielectric layer and the IGZO channel layer. The thicknesses of the $\mathrm{SiO}_{2}$ and the IGZO are approximately $200 \mathrm{~nm}$ and $70 \mathrm{~nm}$, respectively. In Fig. 2(a), the IGZO has a similar microstructure to the $\mathrm{SiO}_{2}$, due to sequential deposition of IGZO on top of $\mathrm{SiO}_{2}$. As previously reported [21], despite the polycrystalline-like microstructure shown in the SEM image, the $\mathrm{SiO}_{2}$ layer is amorphous with an inhomogeneous density distribution due to the porous microstructure. Similarly, the IGZO layer should also be amorphous, which is in agreement with the microstructure of most reported IGZO thin films that are deposited at room temperature $[4,5,22]$.
Fig. 2(b) shows the specific capacitance of the $\mathrm{SiO}_{2}$ gate dielectric using an $\mathrm{Al} / \mathrm{SiO}_{2} / \mathrm{Al}$ sandwich test structure. For conventional, thermally grown $\mathrm{SiO}_{2}$, a 200-nm-thick $\mathrm{SiO}_{2}$ layer would have a capacitance of $17.3 \mathrm{nF} / \mathrm{cm}^{2}$. In Fig. 2(b), the capacitance is $0.22 \mu \mathrm{F} / \mathrm{cm}^{2}$ at $20 \mathrm{~Hz}$ and $0.031 \mu \mathrm{F} / \mathrm{cm}^{2}$ at $100 \mathrm{kHz}$. A possible reason for this frequency dependent capacitance is the low ionic mobility of the mobile protons in the $\mathrm{SiO}_{2}$ dielectric. As indicated in our previous study [21], some water molecules might be absorbed from the ambient air, forming three coordinate oxygen centers, $\mathrm{Si}-\mathrm{OH}^{+}-\mathrm{Si}$, in the $\mathrm{SiO}_{2}$ electrolyte $[18,23]$. The external electric field will force the protons to jump from one hydroxyl group to the next due to the non-stable bonding between hydrogen and oxygen. When a positive bias is applied to the gate electrode, the protons accumulate at the dielectric/channel interface and induce electrons inside the IGZO channel layer to accumulate at the channel/dielectric interface. At low frequencies, the mobile protons inside the $\mathrm{SiO}_{2}$ layer have enough time to accumulate at $\mathrm{SiO}_{2} / \mathrm{Al}$ interface in response to the external electrical field. However, at high frequencies, protons are less able to respond and accumulate at the interface before the electric field switches orientation [24].
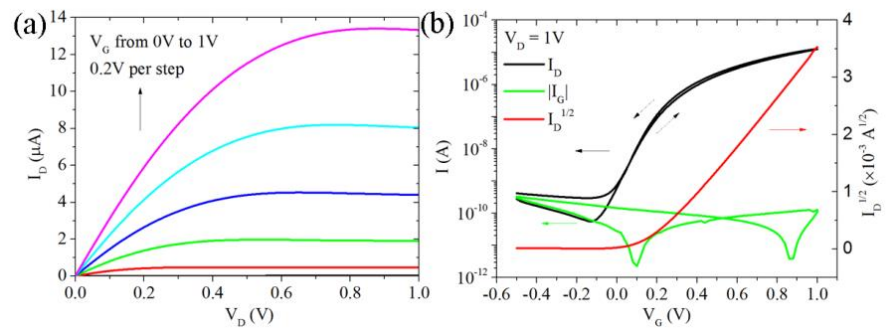

Fig. 3. (a) Output characteristics with $V_{\mathrm{D}}$ swept from $0 \mathrm{~V}$ to $1 \mathrm{~V}$ and $V_{\mathrm{G}}$ swept from $0 \mathrm{~V}$ to $1 \mathrm{~V}$ with a step of $0.2 \mathrm{~V}$. (b) $I_{\mathrm{D}}, I_{\mathrm{D}}{ }^{1 / 2}$ and $I_{\mathrm{G}}$ as a function of $V_{\mathrm{G}}$ from $-0.5 \mathrm{~V}$ to $1 \mathrm{~V}$ at $V_{\mathrm{D}}=1 \mathrm{~V}$.

Fig. 3(a) shows the output characteristics $\left(I_{\mathrm{D}}-V_{\mathrm{D}}\right)$ of the flexible TFTs, indicating the device operates in $n$-type enhancement mode. Drain current, $I_{\mathrm{D}}$, is found to increase linearly with the drain voltage, $V_{\mathrm{D}}$, at low gate voltage, $V_{\mathrm{G}}$. This demonstrates that a good ohmic contact is formed between the $\mathrm{Al}$ source and drain contacts and the IGZO. The estimated contact resistance of the device is less than $10 \%$ of the total channel resistance, even at $V_{\mathrm{G}}=1 \mathrm{~V}$. It is also found that $I_{\mathrm{D}}$ exhibits a clear pinch off and saturates at higher $V_{\mathrm{D}}$. A slight decrease of $I_{\mathrm{D}}$ is observed in the saturation regime, which might be caused by a hot carrier effect and/or selfheating effects [25-28]. Under such effects, charge trapping occurs, resulting in a positive threshold voltage shift and a slight decrease in $I_{\mathrm{D}}$. Fig. 3(b) shows the corresponding transfer characteristics. The devices show an ultralow hysteresis with a current on-off ratio larger than $10^{5}$. The subthreshold swing, $S S$, is found to be $79 \mathrm{mV} / \mathrm{dec}$ for the forward sweep and $84 \mathrm{mV} / \mathrm{dec}$ for the backward sweep, both of which are very close to the theoretical minimum [29]. The gate leakage current, $I_{\mathrm{G}}$, is less than $0.4 \mathrm{nA}$, which is smaller than the previously reported EDL transistors gated with polymer electrolytes or ionic liquids [12, 30]. Fig. 3(b) also displays the transfer characteristics as $I_{\mathrm{D}}{ }^{1 / 2}-V_{\mathrm{G}}$, by which a threshold voltage, $V_{\mathrm{TH}}$, of $0.22 \mathrm{~V}$ is extracted.

In the saturation region $\left(V_{\mathrm{D}}>V_{\mathrm{G}}-V_{\mathrm{TH}}\right)$, 


$$
I_{D}=\frac{1}{2} \frac{W}{L} \mu C\left(V_{G}-V_{T H}\right)^{2}
$$

where, $W / L$ is the ratio of channel width and length, $C$ is the capacitance per unit area. By using the capacitance at $20 \mathrm{~Hz}$ $\left(\sim 0.22 \mu \mathrm{F} / \mathrm{cm}^{2}\right)$, the mobility, $\mu$, is estimated to be $\sim 5.6 \mathrm{~cm}^{2} / \mathrm{Vs}$, which is reasonable and can be further improved by reducing the channel thickness or by thermal annealing [31, 32].
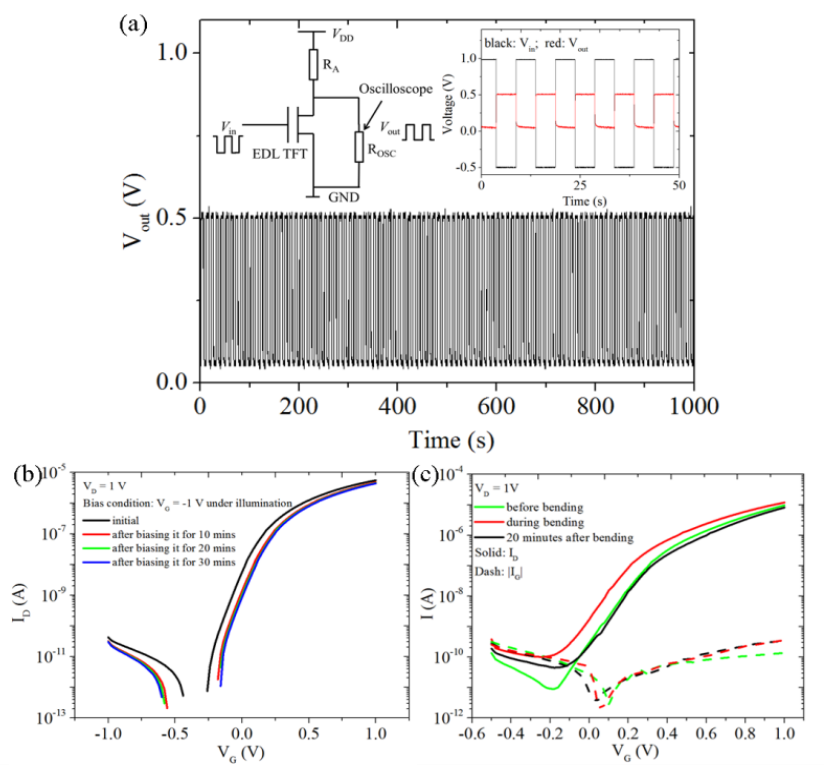

Fig. 4. (a) Switching stability driven by a $0.1 \mathrm{~Hz}$ square wave pulse between $-0.5 \mathrm{~V}$ and $1 \mathrm{~V}$ at $V_{\mathrm{DD}}=1 \mathrm{~V}$. Inset shows the test circuit and a zoom in part of the input voltage and output voltage against time. (b) Transfer characteristics at a constant $V_{\mathrm{D}}$ of $1 \mathrm{~V}$ before and after bias stress. (c) Transfer characteristics with $V_{\mathrm{G}}$ swept from $-0.5 \mathrm{~V}$ to $1 \mathrm{~V}$ at a constant $V_{\mathrm{D}}$ of $1 \mathrm{~V}$ before and after bending

In order to study the switching stability, the device was tested by connecting it with a $1 \mathrm{M} \Omega$ resistor in an inverter setup, as shown in the left inset of Fig. 4(a). The supply voltage, $V_{\mathrm{DD}}$, was fixed at $1 \mathrm{~V}$ and the input signal was a $0.1 \mathrm{~Hz}$ square wave between $-0.5 \mathrm{~V}$ and $1 \mathrm{~V}$. The right inset of Fig. 4(a) clearly shows an on to off switch in the output voltage, suggesting the device works as an inverter. The output voltage is $0.5 \mathrm{~V}$ in the on state because the internal resistance of the oscilloscope is $1 \mathrm{M} \Omega\left(R_{\mathrm{OSC}}\right.$ in Fig. 4(a)). The whole circuit was tested for $1000 \mathrm{~s}$ and no obvious output voltage drop was observed, indicating that the EDL TFTs have good switching stability. The device was also tested by continuously biasing it at $V_{\mathrm{G}}=-1 \mathrm{~V}$ and $V_{\mathrm{D}}=1 \mathrm{~V}$ under illumination (2000 lx white LED, $3 \mathrm{~cm}$ away from the device), and only a $+0.06 \mathrm{~V}$ threshold voltage shift was observed after 30 minutes, as shown in Fig. 4(b). It is possible that the stability of the devices can be further improved by adding a capping layer to passivate the top surface of the devices [33].

$$
\text { Table I }
$$

$C / A\left(\mathrm{NF} / \mathrm{CM}^{2}\right)$ AT $100 \mathrm{HZ}$ BEFORE AND AFTER BENDING

\begin{tabular}{cccccc} 
Sample number & 1 & 2 & 3 & 4 & 5 \\
Before bending & 179 & 185 & 159 & 165 & 155 \\
After bending & 179 & 183 & 160 & 164 & 159 \\
\hline
\end{tabular}

The electrical properties of the flexible TFTs were also measured on a curved surface with a $3.5 \mathrm{~cm}$ radius of curvature, as shown in Fig. 1(b). Several samples were measured and the gate capacitance was found to be almost the same before and after bending, as summarized in Table I. Also, the devices showed no breakdown even after a gate bias up to $5 \mathrm{~V}$ before and after bending. Fig. 4(c) shows the transfer characteristics of the device at $1 \mathrm{~V}$ drain voltage before and after bending. The green curve (before bending) and red curve (during bending) show the current on-off ratio decreases from about $10^{6}$ to $10^{5}$ due to increase of the off current. It is possible that during bending, the distance between atoms in every layer of the transistor increased, resulting in an effective decrease in the energy level splitting of the bonding and antibonding orbitals between the atoms in the IGZO layer [34]. Therefore, some donor electrons might be able to reach the antibonding state after bending, resulting in the increase of off current and a threshold voltage left shift of about $0.07 \mathrm{~V}$ [35]. The device was tested again 20 minutes after being removed from the bending holder. The black curve (20 minutes after removal from the holder) shows a decrease in off current and a slight right shift of the threshold voltage when comparing with the red one (before removing from the holder). The comparison of the black curve and green curve indicates the change induced by bending is reversible. Throughout the whole test the current on-off ratio remained $>10^{5}$ and the subthreshold swing was $<0.12 \mathrm{~V} / \mathrm{dec}$. These results are maintained even after several bending events.

Some groups have reported flexible IGZO TFTs before [3639]. Hsu et al. reported an IGZO TFT on a polycarbonate substrate that could achieve a $S S$ of $\sim 0.13 \mathrm{~V} / \mathrm{dec}$ after being bent to a curve with $3.5 \mathrm{~cm}$ curvature radius [36]. Lee and coworkers reported an IGZO TFT on a thin glass substrate and the obtained results show a threshold voltage change of $0.25 \mathrm{~V}$ and a $S S$ of $\sim 0.28 \mathrm{~V} / \mathrm{dec}$ after being bent to a curve with $4 \mathrm{~cm}$ curvature radius [37]. Thus, the electrical properties of our devices match, and even surpass, those of other IGZO TFTs under similar bending conditions. Moreover, thanks to the formation of the EDL, an operating voltage of $1 \mathrm{~V}$ is achieved in our devices.

In conclusion, we reported flexible EDL transistors that are fabricated using an industry-compatible sputtering process at room temperature. The work might have important implications in future large-scale, low-cost manufacturing of wearable electronics where a low operating voltage and mechanical flexibility are necessary.

\section{REFERENCES}

[1] H. Yabuta, M. Sano, K. Abe, T. Aiba, T. Den, H. Kumomi, K. Nomura, T. Kamiya, and H. Hosono, "High-mobility thin-film transistor with amorphous $\mathrm{InGaZnO}_{4}$ channel fabricated by room temperature rf-magnetron sputtering," App. Phys. Lett., vol. 89, p. 2123, 2006. DOI: $10.1063 / 1.2353811$

[2] T. Hirao, M. Furuta, T. Hiramatsu, T. Matsuda, C. Li, H. Furuta, H. Hokari, M. Yoshida, H. Ishii, and M. Kakegawa, "Bottom-gate zinc oxide thin-film transistors (ZnO TFTs) for AM-LCDs," IEEE Trans. on Electron Devices, vol. 55, pp. 3136-3142, 2008. DOI: 10.1109/TED.2008.2003330

[3] W. Lim, J. H. Jang, S.-H. Kim, D. Norton, V. Craciun, S. Pearton, F. Ren, and H. Shen, "High performance indium gallium zinc oxide thin film transistors fabricated on polyethylene terephthalate substrates," App. Phys. Lett., vol. 93, 2008. DOI: 10.1063/1.2975959

[4] J. S. Lee, S. Chang, S.-M. Koo, and S. Y. Lee, "High-performance a-IGZO TFT with $\mathrm{ZrO}_{2}$ gate dielectric fabricated at room 
temperature,"IEEE Electron Device Lett., vol. 31, pp. 225-227, 2010. DOI: 10.1109/LED.2009.2038806

[5] K. Nomura, H. Ohta, A. Takagi, T. Kamiya, M. Hirano, and H. Hosono, "Room-temperature fabrication of transparent flexible thin-film transistors using amorphous oxide semiconductors," Nature, vol. 432, pp. 488-492, 2004. DOI: 10.1038/nature03090

[6] I.-D. Kim, Y. Choi, and H. L. Tuller, "Low-voltage $\mathrm{ZnO}$ thin-film transistors with high-K $\mathrm{Bi}_{1.5} \mathrm{Zn}_{1.0} \mathrm{Nb}_{1.5} \mathrm{O}_{7}$ gate insulator for transparent and flexible electronics," App. Phys. Lett., vol. 87, 2005. DOI: $10.1063 / 1.1993762$

[7] J. Collet, O. Tharaud, A. Chapoton, and D. Vuillaume, "Lowvoltage, $30 \mathrm{~nm}$ channel length, organic transistors with a selfassembled monolayer as gate insulating films," App. Phys. Lett., vol. 76, pp. 1941-1943, 2000. DOI: 10.1063/1.126219

[8] M.-H. Yoon, H. Yan, A. Facchetti, and T. J. Marks, "Low-voltage organic field-effect transistors and inverters enabled by ultrathin cross-linked polymers as gate dielectrics," J. Am. Chem. Soc., vol. 127, pp. 10388-10395, 2005. DOI: 10.1021/ja052488f

[9] L. Zhang, J. Li, X. Zhang, X. Jiang, and Z. Zhang, "High performance ZnO-thin-film transistor with $\mathrm{Ta}_{2} \mathrm{O}_{5}$ dielectrics fabricated at room temperature," App. Phys. Lett., vol. 95, p. 2112, 2009. DOI: 10.1063/1.3206917

[10] C. Zhou, X. Wang, S. Raju, Z. Lin, D. Villaroman, B. Huang, H. L.-W. Chan, M. Chan, and Y. Chai, "Low voltage and high ON/OFF ratio field-effect transistors based on CVD $\mathrm{MoS}_{2}$ and ultra high-к gate dielectric PZT," Nanoscale, vol. 7, pp. 86958700, 2015. DOI: $10.1039 / C 5 N R 01072 A$

[11] S. Tan, "Challenges and performance limitations of high-к and oxynitride gate dielectrics for 90/65nm CMOS technology," Microelectr. J., vol. 38, pp. 783-786, 2007. DOI: 10.1016/j.mejo.2007.04.012

[12] H. Yuan, H. Shimotani, A. Tsukazaki, A. Ohtomo, M. Kawasaki, and Y. Iwasa, "High-Density Carrier Accumulation in $\mathrm{ZnO}$ FieldEffect Transistors Gated by Electric Double Layers of Ionic Liquids," Adv. Funct. Mater., vol. 19, pp. 1046-1053, 2009. DOI: 10.1002/adfm.200801633

[13] J. Pu, Y. Yomogida, K.-K. Liu, L.-J. Li, Y. Iwasa, and T. Takenobu, "Highly flexible $\mathrm{MoS}_{2}$ thin-film transistors with ion gel dielectrics," Nano Lett., vol. 12, pp. 4013-4017, 2012. DOI: $10.1021 / \mathrm{nl} 301335 \mathrm{q}$

[14] J. Sun, J. Jiang, A. Lu, B. Zhou, and Q. Wan, "Low-Voltage Transparent Indium-Zinc-Oxide Coplanar Homojunction TFTs Self-Assembled on Inorganic Proton Conductors," IEEE Trans.on Electron Devices, vol. 58, pp. 764-768, 2011. DOI: 10.1109/TED.2010.2101604

[15] M. Yamada, D. Li, I. Honma, and H. Zhou, "A Self-Ordered, Crystalline Glass, Mesoporous Nanocomposite with High Proton Conductivity of $2 \times 10^{-2} \mathrm{~S} \mathrm{~cm}^{-1}$ at Intermediate Temperature," $J$. Am. Chem. Soc., vol. 127, pp. 13092-13093, 2005. DOI: 10.1021/ja052914x

[16] J. Sun, J. Jiang, A. Lu, and Q. Wan, "One-Volt Oxide Thin-Film Transistors on Paper Substrates Gated by $\mathrm{SiO}_{2}$ Based Solid Electrolyte With Controllable Operation Modes," IEEE Trans on Electron Devices, vol. 57, pp. 2258-2263, 2010. DOI: 10.1109/TED.2010.2052168

[17] J. Sun, Q. Wan, A. Lu, and J. Jiang, "Low-voltage electric-doublelayer paper transistors gated by microporous $\mathrm{SiO}_{2}$ processed at room temperature," App. Phys. Lett., vol. 95, p. 2108, 2009. DOI: $10.1063 / 1.3270001$

[18] J. Jiang, Q. Wan, J. Sun, and A. Lu, "Ultralow-voltage transparent electric-double-layer thin-film transistors processed at roomtemperature," App. Phys. Lett., vol. 95, p. 152114, 2009. DOI: $10.1063 / 1.3251782$

[19] H. Kurtz and S. Karna, "Proton mobility in a-SiO 2 ," IEEE Trans on Nuclear Science, vol. 46, pp. 1574-1577, 1999. DOI: $10.1109 / 23.819123$

[20] W. Cai, X. Ma, J. Zhang, and A. Song, "Transparent Thin-Film Transistors Based on Sputtered Electric Double Layer," Materials, vol. 10, p. 429, 2017. DOI: 10.3390/ma10040429

[21] X. Ma, J. Zhang, W. Cai, H. Wang, J. Wilson, Q. Wang, Q. Xin, and A. Song, "A Sputtered Silicon Oxide Electrolyte for HighPerformance Thin-Film Transistors," Sci. Rep., vol. 7, p. 809, 2017. DOI: 10.1038/s41598-017-00939-6

[22] K. Nomura, A. Takagi, T. Kamiya, H. Ohta, M. Hirano, and H. Hosono, "Amorphous oxide semiconductors towards high- performance flexible thin-film transistors," Jpn. J. Appl. Phys., vol. 45, pp. 4303-4308, 2006. DOI: 10.1143/JJAP.45.4303

L.-Q. Guo, Y.-Y. Yang, L.-Q. Zhu, G.-D. Wu, J.-M. Zhou, and H.L. Zhang, "Effects of humidity on performance of electric-doublelayer oxide-based thin-film transistors gated by nanogranular $\mathrm{SiO}_{2}$ solid electrolyte," AIP Adv., vol. 3, p. 072110, 2013. DOI: $10.1063 / 1.4815970$

[24] A. Lu and H. Huang, "Low-voltage transparent thin-film transistors with $\mathrm{ZnO} / \mathrm{ITO}$ double-channel layers," Jpn. J. App. Phys., vol. 54, p. 106502, 2015. DOI: 10.7567/JJAP.54.106502

B. Zhang, H. Li, X. Zhang, Y. Luo, Q. Wang, and A. Song, "Performance regeneration of InGaZnO transistors with ultra-thin channels," App. Phys. Lett., vol. 106, p. 093506, 2015. DOI: $10.1063 / 1.4914296$

[26] J. Bardwell, S. Haffouz, W. McKinnon, C. Storey, H. Tang, G. Sproule, D. Roth, and R. Wang, "The effect of surface cleaning on current collapse in AlGaN GaN HEMTs," Electrochem. SolidState Lett., vol. 10, pp. H46-H49, 2007. DOI: 10.1149/1.2402479 Amutha Surabi, J. Chandradass, and S.-J. Park, "ZnO-based thin film transistor fabricated using radio frequency magnetron sputtering at low temperature," Materials and Manufacturing Processes, vol. 30, pp. 175-178, 2015. DOI: $10.1080 / 10426914.2014 .892973$

[28] M.-H. Lee, K.-H. Chang, and H.-C. Lin, "Effective density-ofstates distribution of polycrystalline silicon thin-film transistors under hot-carrier degradation," J. App. Phys., vol. 102, p. 054508, 2007. DOI: $10.1063 / 1.2777804$

[29] V. V. Zhirnov and R. K. Cavin, "Nanoelectronics: Negative capacitance to the rescue?," Nat. Nanotech., vol. 3, pp. 77-78, 2008. DOI: $10.1038 /$ nnano.2008.18

[30] S. Ono, S. Seki, R. Hirahara, Y. Tominari, and J. Takeya, "Highmobility, low-power, and fast-switching organic field-effect transistors with ionic liquids," App. Phys. Lett., vol. 92, p. 103313, 2008. DOI: $10.1063 / 1.2898203$

[31] K. Nomura, T. Kamiya, and H. Hosono, "Interface and bulk effects for bias-light-illumination instability in amorphous-In-Ga-Zn-O thin-film transistors," J. Soc. Inf. Disp., vol. 18, pp. 789-795, 2010. DOI: 10.1889/JSID18.10.789

[32] C.-S. Fuh, S. M. Sze, P.-T. Liu, L.-F. Teng, and Y.-T. Chou, "Role of environmental and annealing conditions on the passivation-free In-Ga-Zn-O TFT," Thin Solid Films, vol. 520, pp. 1489-1494, 2011. DOI: 10.1016/j.tsf.2011.08.088

[33] J. Sun, J. Jiang, W. Dou, B. Zhou, and Q. Wan, "Anomalous Threshold Voltage Shift and Surface Passivation of Transparent Indium-Zinc-Oxide Electric-Double-Layer TFTs," IEEE Electron Device Lett, vol. 32, pp. 910-912, 2011. DOI: 10.1109/LED.2011.2146226

[34] A. d. J. de Meux, G. Pourtois, J. Genoe, and P. Heremans, "Comparison of the electronic structure of amorphous versus crystalline indium gallium zinc oxide semiconductor: structure, tail states and strain effects," J. PhyS. D: Appl. Phys, vol. 48, p. 435104, 2015. DOI: 10.1088/0022-3727/48/43/435104

[35] N. Munzenrieder, K. H. Cherenack, and G. Troster, "The effects of mechanical bending and illumination on the performance of flexible IGZO TFTs," IEEE Trans. on Electron Devices, vol. 58, pp. 2041-2048, 2011. DOI: 10.1109/TED.2011.2143416

[36] H.-H. Hsu, C.-Y. Chang, and C.-H. Cheng, "A Flexible IGZO Thin-Film Transistor With Stacked $\mathrm{TiO}_{2}$-Based Dielectrics Fabricated at Room Temperature," IEEE Electron Device Lett, vol. 34, pp. 768-770, 2013. DOI: 10.1109/LED.2013.2258455

[37] G. J. Lee, J. Kim, J.-H. Kim, S. M. Jeong, J. E. Jang, and J. Jeong, "High performance, transparent a-IGZO TFTs on a flexible thin glass substrate," Semicond. Sci. Technol, vol. 29, p. 035003, 2014. DOI: $10.1088 / 0268-1242 / 29 / 3 / 035003$

[38] H.-H. Hsu, C.-Y. Chang, and C.-H. Cheng, "Room-temperature flexible thin film transistor with high mobility," Current Applied Physics, vol. 13, pp. 1459-1462, 2013. DOI: 10.1016/j.cap.2013.04.026

[39] C.-Y. Lin, C.-W. Chien, C.-C. Wu, Y.-H. Yeh, C.-C. Cheng, C.-M. Lai, M.-J. Yu, C.-M. Leu, and T.-M. Lee, "Effects of mechanical strains on the characteristics of top-gate staggered a-IGZO thinfilm transistors fabricated on polyimide-based nanocomposite substrates," IEEE Trans on Electron Devices, vol. 59, pp. 19561962, 2012. DOI: 10.1109/TED.2012.2193585 